\title{
Suprapineal recess diverticulum of the third ventricle exerting a mass effect on the midbrain and cerebellum
}

Divertículo do recesso suprapineal do terceiro ventrículo: efeito de massa sobre o mesencéfalo e cerebelo

Mariana Athaniel Silva Rodrigues ${ }^{1}$, Thiago Pereira Rodrigues², Marcos Devanir Silva da Costa², Samuel Tau Zymberg², Italo C. Suriano², Sérgio Cavalheiro²

Ventricular diverticula usually occur secondary to chronic obstructive hydrocephalus, due to long-standing pulsating of cerebrospinal fluid against the ventricle wall ${ }^{1,2}$. The medial wall of the atrium is more frequently involved $^{1,3,4}$, but other ventricle sites are at risk as well ${ }^{2}$. We report on a 21-year-old woman with chronic headache and

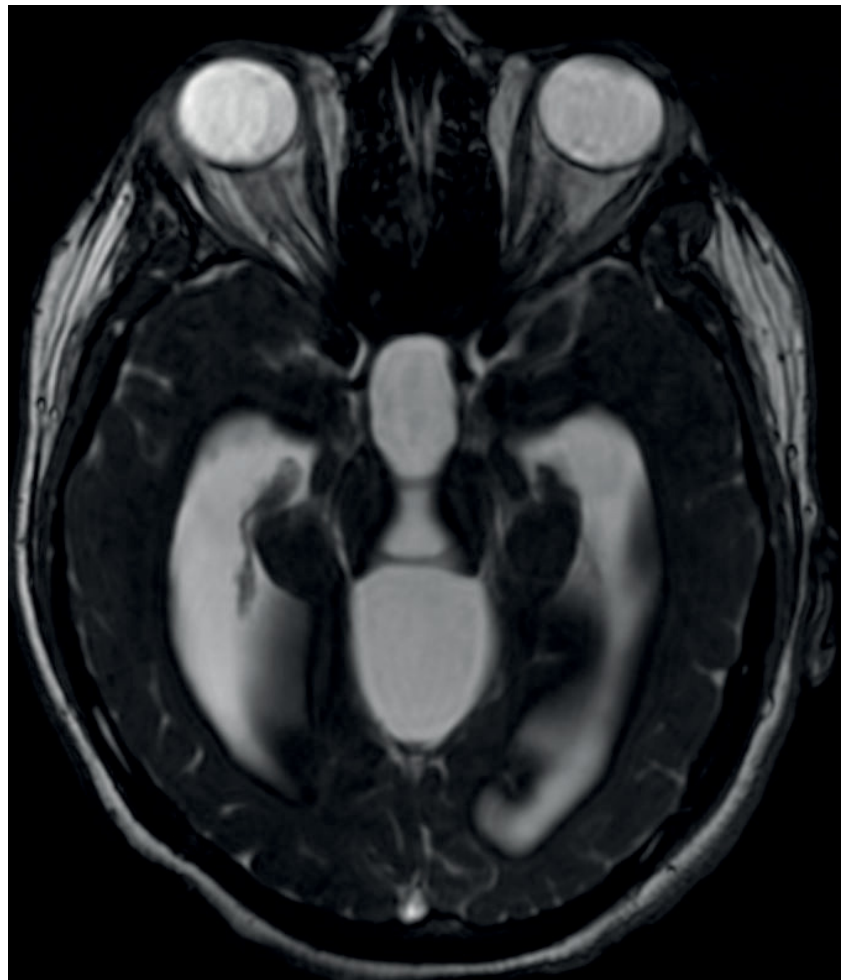

Figure 1. The preoperative axial T2-weighted fast spin echo imaging shows a large retromesencephalic cyst. bilateral dysmetria. Magnetic resonance imaging showed a ventricular diverticulum on the posterior wall of the third ventricle with a cerebellar and midbrain mass effect (Figures 1-4). Her symptoms partially improved after endoscopic third ventriculostomy in the tuber cinereum region. Treatment of chronic hydrocephalus has been shown to improve the ventricular diverticulum symptoms in the patients in the literature ${ }^{1,2,3,4,5}$.

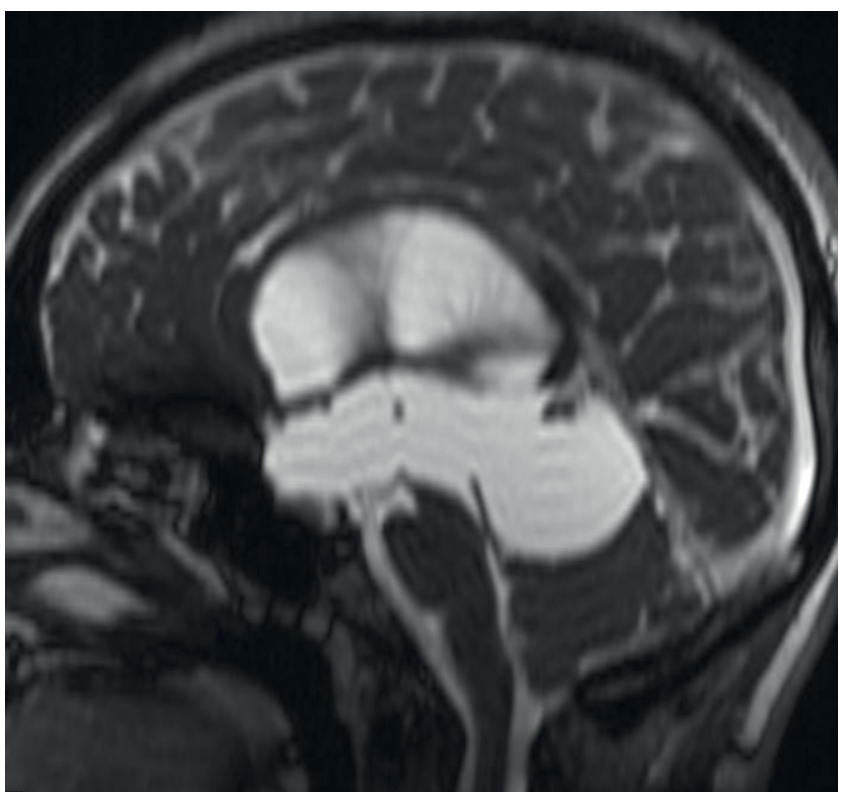

Figure 2. The preoperative midline sagittal T2-weighted fast spin echo imaging shows the third ventricle posterior wall diverticulum exerting a mass effect on both the midbrain and cerebellum. Also, there is an obstruction point in the cerebral aqueduct.

\footnotetext{
1 Hospital Israelita Albert Einstein, São Paulo SP, Brazil;

2 Universidade Federal de São Paulo, Hospital São Paulo, São Paulo SP, Brazil.
}

Correspondence:Thiago Pereira Rodrigues; Rua das Camélias, 29 / apto. 31, Mirandópolis; 04048-060 São Paulo SP, Brazil. E-mail:thiagopereirarodrigues@ yahoo.com.br

Conflict of interest: There is no conflict of interest to declare.

Received 28 April 2018; Accepted 14 May 2018. 


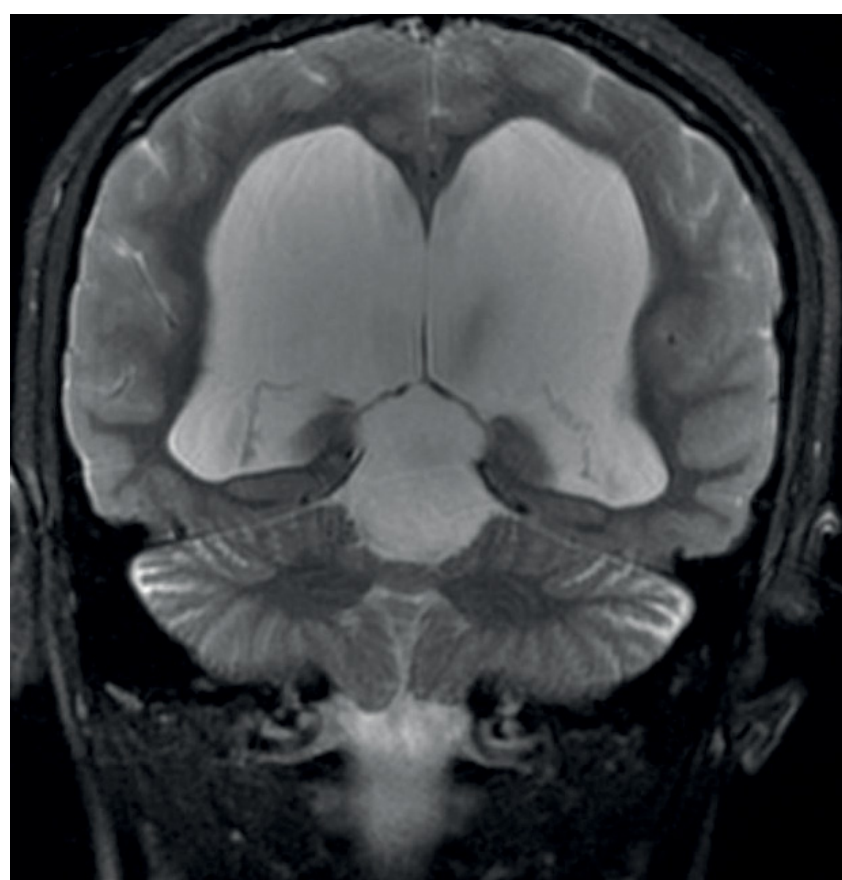

Figure 3. The preoperative coronal T2-weighted fast spin echo imaging at the level of the lateral ventricular atrium shows integrity of the medial wall of both lateral ventricular atria, suggesting that the posterior wall of the third ventricle is involved in this posterior fossa cyst genesis.

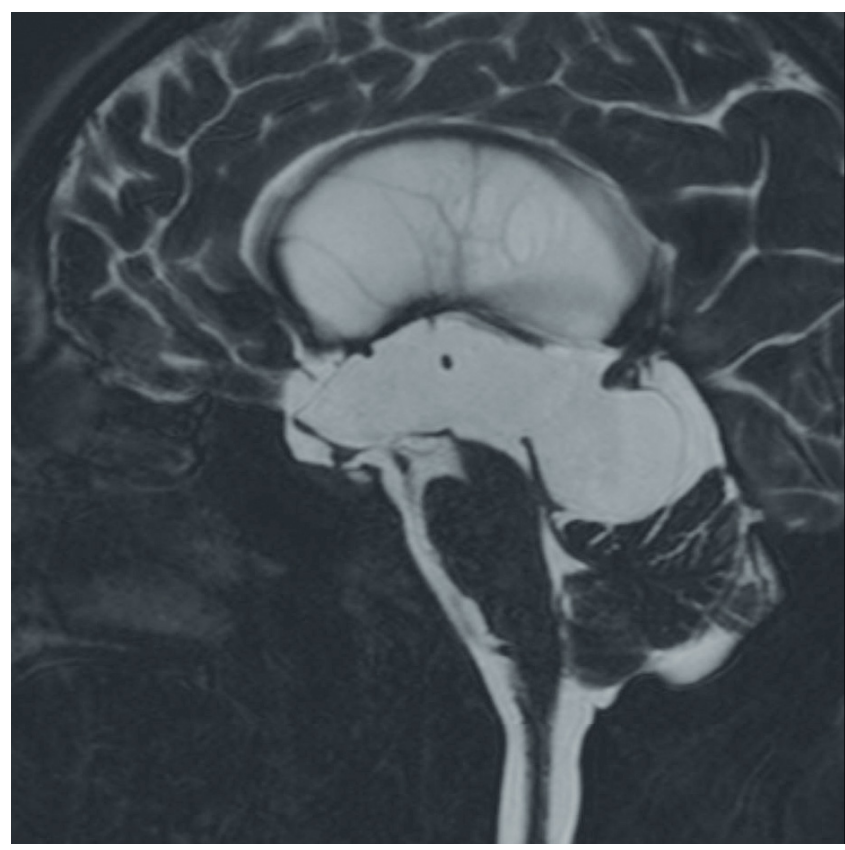

Figure 4. The postoperative midline sagittal T2-weighted fast spin echo shows reduction of the cyst size. The posterior wall of the third ventricle is now visualized and is separated from the tentorium and tentorial face of the cerebellum. Also seen is the lamina terminalis, which forms the anterior wall of the third ventricle.

\section{References}

1. Jabaudon D, Charest D, Porchet F. Pathogenesis and diagnostic pitfalls of ventricular diverticula: case report and review of the literature. Neurosurgery. 2003 Jan;52(1):209-12.

2. Tedeschi E, Rapanà A, Elefante A, De Liso M, Morrone R, laccarino C. Expansion diverticulum of the suprapineal recess causing cerebellar ataxia: a case report. Neuroradiol J. 2013 Apr;26(2):163-7. https://doi.org/10.1177/197140091302600205
3. Wakai S, Narita J, Hashimoto K, Nagai M. Diverticulum of the lateral ventricle causing cerebellar ataxia: case report. J Neurosurg. 1983 Nov;59(5):895-8. https://doi.org/10.3171/jns.1983.59.5.0895

4. Wakai S, Nagai M. Ventricular diverticulum.J Neurol Neurosurg Psychiatry. 1984 May;47(5):514-7. https://doi.org/10.1136/jnnp.47.5.514

5. Daniel RT, Lee GY, Reilly PL. Suprapineal recess: an alternate site for third ventriculostomy? Case report. J Neurosurg. 2004 Sep;101(3):518-20. https://doi.org/10.3171/jns.2004.101.3.0518 